\title{
Tracking of COVID-19 in Libya
}

\author{
Aisha Nasef* and Adel El Taguri \\ ${ }^{1}$ Authority of Natural Science Research and Technology, Medical Specialty Council, Libya \\ ${ }^{2}$ Department of community Medicine, University of Tripoli, Libya
}

Received: 10 April, 2020
Accepted: 26 May, 2020
Published: 27 May, 2020

*Corresponding author: Aisha Nasef, Authority of Natural Science Research and technology, Medical Specialty Council, Libya, E-mail: nasef@doctor.com Keywords: Corona; COVID-19; Libya; Epidemiological https://www.peertechz.com

\section{Introduction}

We read with interest the article entitled "Preliminary epidemiological analysis of suspected cases of corona infection in Libya" published by Dr. Daw MA, 2020. The author acknowledged the declaration of Coronavirus Disease 2019 (COVID-19) pandemic and the difficulties in application of WHO and CDC measures in conflict areas such as Libya.

\section{Epidemiological, clinical and laboratory data}

We noticed that the article was submitted on 16 March and was published online on 20 March. This was eight days earlier than the official declaration of the first case of COVID-19 in Libya. The author did not report about the required legally mandatory notification of the cases to the local health authorities. This is of a great concern, due to the nature of infection and the fragility of the Libyan HealthCare systems.

There was no information about the time of conducting the research, its place, and eventual admission of the patients to intensive care units. There were no comments about respiratory symptoms especially respiratory rate and/ or dyspnea. Laboratory investigation did not include hypoxia assessment and blood gas results were not reported even for the two patients who died.

Total number of patients were eight, but in reporting about the radiological findings, six patients $(75 \%)$ had bilateral pneumonia and three patients $(38 \%)$ had unilateral pneumonia, which make a total of nine different presentations.

We were wondering whether in reality there were findings of unilateral pneumonia in two patients (25\%) and multiple mottling in three patients $(38 \%)$.

The author reported negative results for screening of respiratory viruses. There was no mention of the types of respiratory infections that were looked for. This is of paramount importance as some of the resources required might not be available, and many diseases such as Influenza $\mathrm{A}$ and $\mathrm{B}$ viruses, respiratory syncytial virus, parainfluenza virus, adenovirus, or COVID like viruses such as Sever Acute Respiratory Syndrome (SARS), or Middle East Respiratory Syndrome (MERS) could present with similar range of clinical pictures. In addition, the diagnosis of these patients was not confirmed by the recommended Polymerase Chain reaction (RT-qPCR) or other accepted tests. Moreover, it is known now that C-reactive Protein (CRP) and Angiotensin II levels among others are markedly elevated and are linearly associated to viral load, acute lung injury and prognosis. Unfortunately, these testes either were not performed or were not reported by the author.

The author reported the death of two patients out of the eight patients $(25 \%)$. This is particularly a high case fatality rate from COVID-19 in comparison to reported figures on other parts of the world. This is of particular concern as, no data was mentioned about associated comorbidities, but the laboratory investigations reported that six patients were diabetics and six were anemic. The number of cases in this study is small, and no conclusive mortality rate can be withdrawn in the time being.

As two patients (25\%) passed away, it would be worthy to know if they were patients with ground glass opacity, as it is usually found in the second week of COVID-19 infection.

It is not clear whether these suspected cases were informed about their possible diagnosis and eventual consent for this publication. Patient's isolation seems to be practiced according to scoring criteria based on travel history, clinical finding and circumstantial radiological and laboratory investigation.

The author mentioned that the patients were treated according to international standards. Looking back to referenced protocol of treatment, it includes anti-viral drugs and alpha interferons inhalation with use of steroids and gamma immunoglobulins in certain indications. It's not clear why they adopt this treatment protocol as investigations did 
not reveal any evidence of other viral infection and COVID-19 was not confirmed.

\section{Migration and spread of pandemic}

The author had pointed out that migrants going through Libyan shores could endanger southern Europe countries. However we know that the number of cases are already beyond control in Europe (Italy: >119,000, Spain: $>124,000$ and USA: $>278,000$ with mortalities on 4 April that mount to $>3,300$ in China, $>14,600$ in Itlay, $>11,700$ in Spain and $>74000$ in USA). Neither Libya, nor most African countries from where migrants do usually come are implicated in the pandemic until now [1].

The author rightly called for international efforts to be coordinated to fight the pandemic. Unfortunately, the shortcomings of the global health system and the low morals levels highlighted the importance of country-based efforts. Early detection and reporting to local health authority are of primordial importance in such efforts.

\section{Infection pattern and national health authority stand}

The official declaration of the first case of COVID-19 in Libya was on $24^{\text {th }}$ of March. The patient had visited the Saudi Arabia and returned to Libya on 5 March. He was officially diagnosed 19 days later after his return. The patient did not need intensive care and all his close family members COVID-19 tests were negative. Usually, COVID-19 patients would be infectious to others especially their close contacts early in the course of the disease, even before the appearance of symptoms. This is in contrast to similar diseases as SARS-CoV, which is mostly infectious during the peak of patient's illness, in a time when they are hospitalized with consequent limited mobility and chances of close contact with their entourage. One study showed that COVID-19 median incubation period is five days, and $97.5 \%$ of patients develop symptoms within 11.5 days. However, very small percent will develop symptoms after 14 days of quarantine [2]. COVID-19 is well known to have a fastspreading nature due to highest viral loads near presentation [3], where high load correlated with patient's severe disease [4]. These finding could justify clinical picture in first Libyan case.

Diagnostic criteria of suspected COVID-19 infected cases require one epidemiological and two clinical features or all three clinical features [5]. These patients had a history of travel to epidemic countries and seven among them had fever and/or respiratory symptoms. Other recommended clinical features are normal white blood cells with Lymphopenia and imaging characteristics. These patients have Lymphopenia with abnormal (increased) white blood cells, and characteristics mottling or ground glass appearance were reported only in two patients.
Currently, only 263 person were investigated in Libya because of the suspicion of the COVID-19 with only 17 patients proved to be positive cases. One case has died [6]. In future, the clinical history of infected cases and the results of their laboratory investigation of COVID-19 and COVID like disease, along with identification of genetic sequence of virus isolated from Libyans might bring us certain useful information such as new mutation or other causative agents or confirming peculiar COVID-19 pandemic due to environmental or genetic factors.

\section{Conclusion}

In our opinion, we need a confirmation of COVID-19 cases by evidence-based laboratory and clinical means according to recognized standards. A discussion and reporting of these suspected cases to corresponding health authority, medical staff and public is mandatory in timely manner.

We praise the author for his close and timely follow-up of COVID-19 suspected cases, as this would help optimize management in this group of patients. Low population density in Libya, absence of humidity and very small InterCity's movements, could have a positive role in prevention of infection outbreak [7]. This should not by any mean divert us from the more cost-effective actions that was proved to be effective in China, with national plan comprising the "Four Es" or so called $4 \mathrm{E}$ strategy (early detection, early reporting, early isolation, early treatment) especially in the context of the fragile Libyan healthcare system.

\section{References}

1. Link: https://bit.ly/2X42z8S

2. Lauer SA, Grantz KH, Bi Q, Jones FK, Zheng Q, et al. (2020) The Incubation Period of Coronavirus Disease 2019 (COVID-19) From Publicly Reported Confirmed Cases: Estimation and Application. Ann Intern Med. Link: https://bit.ly/3c5pLrN

3. To KK, Tsang OT, Leung WS, Tam AR, Wu TC, et al. (2020) Temporal profiles of viral load in posterior oropharyngeal saliva samples and serum antibody responses during infection by SARS-CoV-2: an observational cohort study. Lancet Infect Dis 20: 565-574. Link: https://bit.ly/36Aipex

4. Liu Y, Yang Y, Zhang C, Huang F, Wang F, et al. (2020) Clinical and biochemical indexes from 2019-nCoV infected patients linked to viral loads and lung injury. Sci China Life Sci 63: 364-374. Link: https://bit.ly/2A93FY4

5. The knowledge center for china's experiences in response to COVID-19. Diagnosis and treatment protocol of COVID-19 in China. Link: https://bit.ly/36zXVTy

6. https://bit.ly/3d6V4DN

7. Investigation of effective climatology parameters on COVID-19 outbreak in Iran. Science of the Total Environment 729: 138705. Link: https://bit.ly/2zA0F71

Copyright: (c) 2020 Nasef A, et al. This is an open-access article distributed under the terms of the Creative Commons Attribution License, which permits unrestricted use, distribution, and reproduction in any medium, provided the original author and source are credited. 